CLINICAL STUDY

\title{
Thyrotoxic adenoma followed by atypical hyperthyroidism due to struma ovarii: clinical and genetic studies
}

\author{
Antonio Ciccarelli ${ }^{1,4}$, Hernan Valdes-Socin ${ }^{1}$, Jasmine Parma ${ }^{2}$, Sok Kean Khoo ${ }^{3}$, Jacqueline Schoumans ${ }^{3}$, \\ Annamaria Colao ${ }^{4}$, Etienne Hamoir ${ }^{5}$ and Albert Beckers ${ }^{1}$ \\ ${ }^{1}$ Department of Endocrinology, Liège University, Liège, Belgium, ${ }^{2}$ Institute of Interdisciplinary Research, Campus Erasme, Bruxelles University, \\ Brussels, Belgium, ${ }^{3}$ Van Andel Research Institute, Grand Rapids, MI, USA, ${ }^{4}$ Department of Molecular and Clinical Endocrinology and Oncology, \\ Federico II University, Naples, Italy and ${ }^{5}$ Department of Endocrine Surgery, Liège University, Liège, Belgium
}

(Correspondence should be addressed to Albert Beckers, Service d'Endocrinologie, CHU de Liège, Domaine Universitaire du Sart-Tilman 4000 Liège, Belgium; Email: albert.beckers@chu.ulg.ac.be)

(Antonio Ciccarelli and Hernan Valdes-Socin contributed equally to this study)

\begin{abstract}
Objective: Atypical forms of hyperthyroidism represent a diagnostic challenge for clinicians. Struma ovarii is an ovarian teratoma and constitutes a rare cause of ectopic thyroidal hormonal production. We describe a case of struma ovarii that combined two different sources of hyperthyroidism in the same patient and report genetic studies in order to contribute a better understanding of the autonomy and tumorigenesis of the struma ovarii.

Case report: A 73-year-old nulliparous woman presented a thyroid toxic adenoma that was successfully treated with $10 \mathrm{mCi}$ radioiodine. Unexpectedly, a new onset of hyperthyroidism prompted us to look for a second etiology. A whole-body scan with ${ }^{123} \mathrm{I}$ detected a pelvic hyperfixation suggesting struma ovarii, and a thyroid differentiated left ovarian teratoma $3 \mathrm{~cm}$ in size was surgically removed. We screened for mutations of thyroid-stimulating hormone receptor and Gs- $\alpha$ protein genes, as these mutations are common in thyroid adenomas. We did not identify any mutations. Androgen receptor study demonstrated a monoclonal status. Comparative genomic hybridization did not reveal any chromosomal abnormality. However, loss of heterozygosity analysis showed several structural abnormalities, compared with the majority of benign ovarian teratomas, which show a normal karyotype. Conclusions: This is the first well-documented report of thyrotoxic struma ovarii revealed after treatment of a single thyroid toxic adenoma. We have shown in this case that struma ovarii originates from a single germ cell, and, albeit benign, this tumor presents several chromosomal abnormalities. Struma ovarii-induced hyperthyroidism is likely to be mediated by mechanisms different from those of the classical thyroid toxic adenoma.
\end{abstract}

European Journal of Endocrinology $150431-437$

\section{Introduction}

Thyrotoxicosis is commonly caused by excessive production of thyroid hormones by the thyroid gland, as in Graves' disease, toxic adenoma or toxic multinodular goiter. These and other causes of hyperthyroidism as well are associated with a high 24-h radioiodine uptake (RAI) in the thyroid bed. In contrast, some other causes of thyrotoxicosis are associated with a low 24-h RAI and are classified as atypical forms of hyperthyroidism. These latter represent a diagnostic puzzle for clinicians and may delay a proper management (1). As summarized in Table 1, atypical hyperthyroidism includes thyroid inflammation, iodine-induced hyperthyroidism and/or ectopic secretion of thyroid hormones.

Struma ovarii is a rare, mature ovarian teratoma. Since its first description in 1889, approximately 500 cases have been reported; only 5-15\% are complicated by hyperthyroidism (2). Besides its rarity, the genotypic features of mature ovarian teratoma are disputed $(3,4)$, and the mechanisms underlying hyperthyroidism caused by struma ovarii are still largely unknown.

We report here a woman with atypical hyperthyroidism due to struma ovarii, co-existing with another source of typical hyperthyroidism. A genetic study of this teratoma was carried out to clarify its autonomy and tumorigenesis.

\section{Case report}

A 73-year-old, nulliparous, Caucasian woman had suffered a new onset of palpitations, tachycardia and a weight loss of $14 \mathrm{~kg}$ during the year before admission. Physical examination revealed a tender nodule $2 \mathrm{~cm}$ in size in the right thyroid lobe. Laboratory findings were 
Table 1 Causes of thyrotoxicosis with low radioiodine uptake in thyroid bed.

\section{Subacute thyroiditis}

Struma ovarii

Factitious ingestion of thyroid hormone

Metastatic functional thyroid cancer

lodine-induced hyperthyroidism as follows: thyroid-stimulating hormone $(\mathrm{TSH})<0.01$ $\mu \mathrm{U} / \mathrm{ml}(0.1-4.0)$, free thyroxine $(\mathrm{FT} 4)=2.7 \mathrm{ng} / \mathrm{ml}$ $(0.7-2)$ and free triiodothyronine $(\mathrm{FT} 3)=5 \mathrm{pg} / \mathrm{ml}$ $(1.5-5.5)$, with thyroglobulin antibodies (AbTg), thyroperoxidase antibodies (AbTPO), TSH-receptor antibodies (TRAb), thyroglobulin and calcitonin in the normal range. A $13 \times 8 \times 15 \mathrm{~mm}$ cervical nodule at ultrasonography showed intense ${ }^{123} \mathrm{I}$ uptake. Hypothyroidism was achieved 3 months later after $10 \mathrm{mCi}{ }^{131} \mathrm{I}$ treatment, and levothyroxine replacement was started progressively at a dose of $75 \mu \mathrm{g}$ daily. However, the patient developed tachycardia and biochemically detected hyperthyroidism, prompting us to re-evaluate the thyroid profile without levothyroxine $(\mathrm{TSH}<0.01$ $\mu \mathrm{U} / \mathrm{ml}, \mathrm{FT} 4=2.5 \mathrm{ng} / \mathrm{ml}, \mathrm{FT} 3=3 \mathrm{pg} / \mathrm{ml}$, with AbTg, AbTPO and TRAb in the normal range) on the hypothesis of a residue of toxic adenoma, but a new RAI showed $<1 \%$ uptake in the cervical tract. Since the patient had high consumption of marine salt, a lowsalt diet was initiated. One month later, the urinary iodine level was normal, but hyperthyroidism persisted. Therefore, a whole-body scan with ${ }^{123} \mathrm{I}$ was performed to detect atypical hyperthyroidism. Intense tracer activity was detected in the pelvis. An abdominal radiograph in the planar view demonstrated a pelvic soft tissue density containing calcification; ultrasonography of this region revealed a $12 \times 8 \mathrm{~cm}$ mass, containing both solid and cystic components, located in the left side. No hypervascularization was found by Doppler ultrasound. Magnetic resonance imaging (MRI) of this lesion showed a biloculated mass in T1-weighted images; the solid part of the tumor was heterogeneous and hyperintense in T2-weighted images.

The mass, originating in the left ovary and firmly affixed to the rectosigmoid, was surgically removed. Total anexohysterectomy and partial resection of the sigmoid were performed (Fig. 1). Two weeks postoperatively, TSH had risen to $8 \mu \mathrm{U} / \mathrm{ml}$ and FT4 was $1.2 \mathrm{ng} / \mathrm{ml}$. A control whole-body iodine scan showed a cervical residual uptake. Five years later, the patient was free of symptoms and was receiving replacement therapy with $87.5 \mu \mathrm{g}$ of levothyroxine.

\section{Pathologic studies}

Histology revealed brown thyroid tissue associated with respiratory epithelium and bone tissue. Thyroid tissue measured $2.5 \times 2.5 \times 3 \mathrm{~cm}$. Thyroid follicles varied in

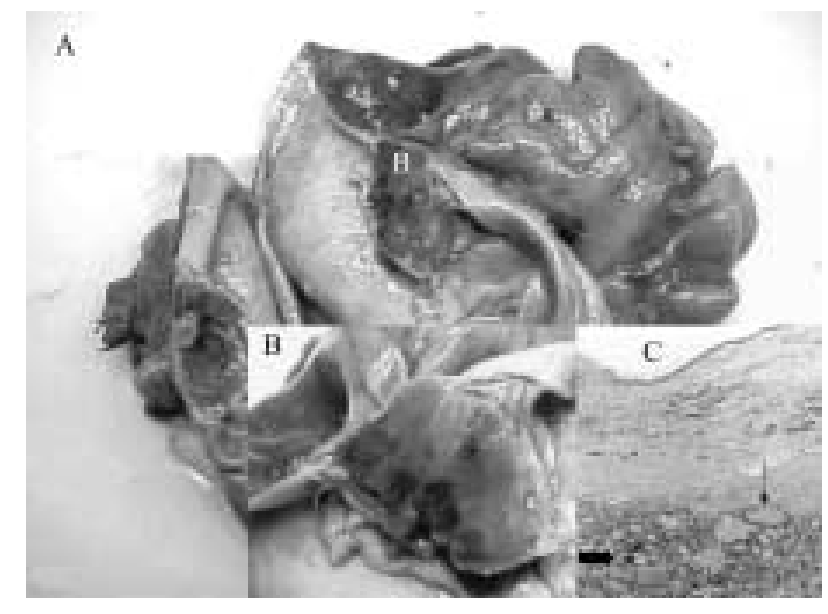

Figure $1 \mathrm{~A}$ : Anexohysterectomy and partial resection of sigmoid. B: Magnification of struma ovary arising from left ovary. C: Histologic examination of struma ovarii (staining type haematoxylineosin; magnification $40 \times$ ). The thyroid follicles $(\downarrow)$ varied in size, with middle and small follicles consisted of cubic epithelium surrounding colloid material staining for thyroglobulin, but not for calcitonin. Fibroinflammatory cells $(\rightarrow$ ) and moderate cytoplasmic vacuolization suggested secondary effects to radioiodine treatment.

size with small and medium follicles consisted of cubic epithelium surrounding colloid material that stained positively with thyroglobulin but negatively with calcitonin. Fibroinflammatory cells and moderate cytoplasmic vacuolization suggested secondary effects of the radioiodine treatment (Fig. 1). Teratoma tissue was immediately stored at $-70^{\circ} \mathrm{C}$ for genetic studies.

\section{Genetic investigations}

\section{1-TSH receptor and Gs- $\alpha$ subunit mutational studies}

Genomic DNA and RNA were isolated from the patient's lymphocytes and tumor. DNA and RNA were analyzed by PCR and RT-PCR respectively and submitted to direct sequencing by standard protocols, to detect either a known germinal or somatic mutation of the receptor of TSH (TSHR) and Gs- $\alpha$ subunit genes.

PCR products were purified and sequenced using the Big Dye cycle sequencing kit (Applied Biosystem, Foster City, CA, USA), and products of sequencing were analyzed on a 377 or 3100 Genetic Analyser (Applied Biosystem). Mutations were investigated using Factura and Sequence Navigator software.

TSH receptor gene The human TSHR gene is located on chromosome $14 \mathrm{q} 31$ (distal position). Most of its known activating mutations are located in exons 9 and 10 (from residue 430 to codon stop). Exon 9 was amplified using intronic primers for genomic DNA, as previously described (5), and exonic primers for cDNA 
(primer direct 5'TGT AAA ACG ACG GCC AGT CGA GCT TGC TGG ACG TGT CT3', the underlined sequence corresponding to universal primer M13D; primer reverse 5'CAG TTT GTA GTG ACT AGT GAG GAG AAT AAG3 $^{\prime}$ ). Region 430-stop of exon 10 was amplified using three fragments, as previously described (6). No mutations were found, but a polymorphism, D727E, was identified in the heterozygote state in both the struma ovarii and the lymphocytes.

Gs- $\alpha$ gene The Gs- $\alpha$ gene is localized on chromosome 20q13 (distal position). Exons 8 and 9 were amplified by PCR using intronic primers for genomic DNA, as previously described (7), and exonic primers for cDNA (primer direct 5' ACT ATG TGC CGA GCG ATC AG 3'; primer reverse $5^{\prime}$ CCC GGA TGA CCA TGT TGT AG $\left.3^{\prime}\right)$. No mutations could be detected.

\section{2-Monoclonality studies}

The androgen receptor (AR) gene is mapped to chromosome Xq11.2-q12 (centromeric position).The human AR gene assay (HUMARA) for the analysis of clonality in tissue from female patients examines the inactivation pattern of this gene on the $\mathrm{X}$ chromosome. This method relies on the length polymorphism of a human AR gene exon, which has restriction sites for methylase-sensitive enzymes (HpaII). Only methylated inactive alleles are preserved after HpaII digestion, and they are amplified by PCR. If the subject is heterozygote at the HUMARA after HpaII digestion, displaying two different alleles would indicate polyclonal origin, whereas the displaying of only one allele would indicate monoclonality. The allele pattern of AR was compared in the patient's tumoral and lymphocytes DNA, as previously described (8). In our case, digestion by HpaII has not been necessary because, by HUMARA PCR amplification of undigested samples, we found a loss of heterozygosity for the AR gene in the tumor tissue, a clear sign of monoclonality (Fig. 2).

\section{3-Comparative genomic hybridization (CGH)}

High molecular weight DNA was extracted from the fresh frozen tumor using standard methods. CGH was performed as previously described (9). Briefly, tumor DNA was labeled with FITC-12-dUTP (DuPont, Boston, MA, USA) by nick translation, and normal reference DNA was labeled with Spectrum Red (Vysis Inc., Downers Grove, IL, USA). Tumor and reference DNAs were mixed with unlabeled Cot-1 DNA (Gibco Invitrogen, Inc., Carlsbad, CA, USA), denatured and applied on to denatured metaphase slides of normal lymphocytes (Vysis Inc.). After hybridization at $37^{\circ} \mathrm{C}$ for $48 \mathrm{~h}$, the slides were washed in $0.4 \times \mathrm{SSC} / 0.3 \%$ $\mathrm{NP}-40$ at $74{ }^{\circ} \mathrm{C}$ for $2 \mathrm{~min}$ and in $2 \times \mathrm{SSC} / 0.1 \% \mathrm{NP}-40$ at room temperature for $1 \mathrm{~min}$. After air-drying, the slides were counterstained with $0.1 \mu \mathrm{g} / \mathrm{ml} \mathrm{4,6-diami-}$ dino-2-phenylindole (DAPI) (Sigma) in an antifade solution (Vectashield, Vector Inc., Burlingame, CA, USA). A control hybridization was also performed using normal female DNA against normal male DNA.

Ten tri-color digital images (DAPI, Applied Spectral Imaging, Carlsbad, CA, USA; FITC and Spectrum Red fluorescence Vysis Inc., Downers Grove, IL, USA) were collected from each hybridization using a Zeiss Axioplan 2 (Carl Zeiss Jena GmbH, Jena, Germany) epifluorescence microscope and a Sensys (Photometrics, Tucson,

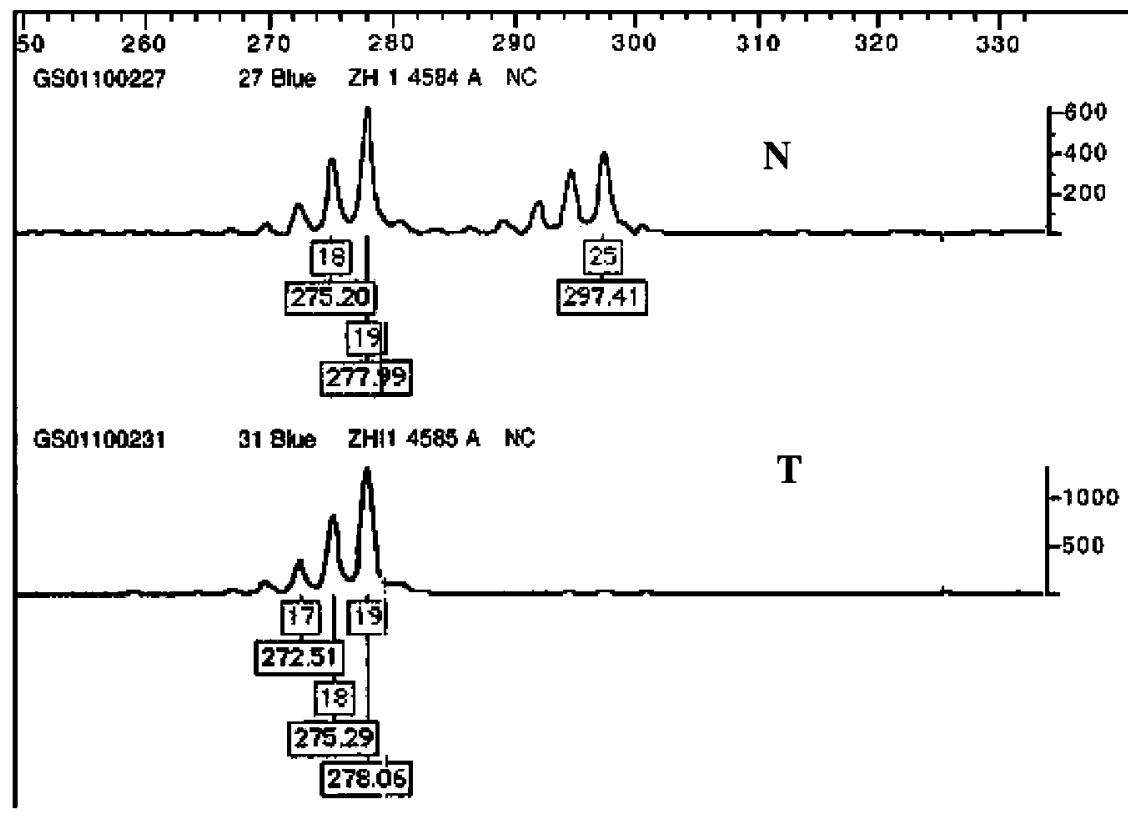

Figure 2 HUMARA PCR amplification of undigested samples showing $\mathrm{LOH}$ for the AR gene in struma ovarii. $\mathrm{N}$ is the matched normal tissue and $\mathrm{T}$ is the tumor tissue. 
AZ, USA) charge-coupled-device camera interfaced to an IPLab Spectrum 10 workstation (Signal Analytics Corporation, Vienna, VA, USA). Relative DNA sequence copy number changes were detected by analyzing the fluorescence intensities of tumor and normal DNAs along the length of all chromosomes in each metaphase spread. The absolute fluorescence intensities were normalized so that the average green-to-red ratio of all chromosomes in each metaphase was 1.0. The final results were plotted as a series of green-to-red ratio profiles and corresponding standard deviations (s.D.) for each human chromosome from p-telomere to q-telomere. At least 12 ratio profiles were averaged for each chromosome to reduce noise. Green-to-red ratios over 1.20 were considered as gains of genetic material, and ratios under 0.80 as losses. Heterochromatic regions, the short arm of the acrocentric chromosomes and chromosome $\mathrm{Y}$ were not included in the evaluation.
We did not find any chromosomal abnormalities in the tumor.

\section{4-Loss of heterozygosity (LOH) analysis}

We further analyzed the tumor and normal tissues for loss of heterozygosity ( $\mathrm{LOH})$. One, two or three microsatellite markers, preferably one from the short (p) arm and another from the long (q) arm, were chosen from ABI Prism Linkage Mapping Set v. 2 (Applied Biosystems, Foster City, CA, USA) for each chromosome: D1S2667, D1S498, D1S249, D2S168, D2S112, D3S1289, D3S1271, D4S391, D4S413, D5S630, D5S436, D6S470, D6S262, D7S513, D7S640, D8S550, D8S284, D9S286, D9S1776, D11S1338, D11S925, D12S99, D12S86, D13S175, D13S170, D14S283, D14S68, D15S165, D15S127, D16S404, D16S515, D17S831, D17S798, D17S949, D18S452,
D7S640

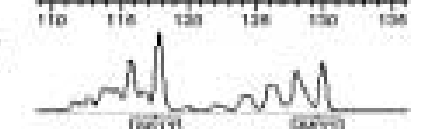

D10S196

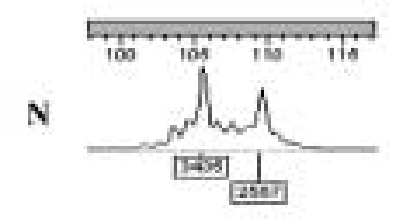

D10S1686

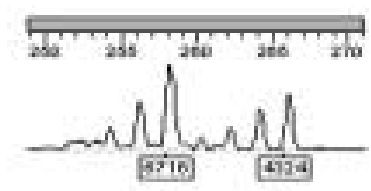

DXS990

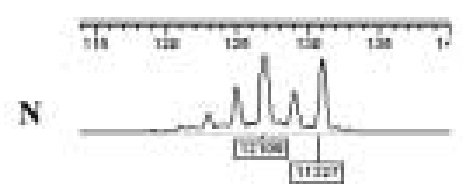

DXS1227

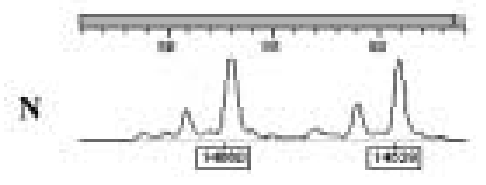

T
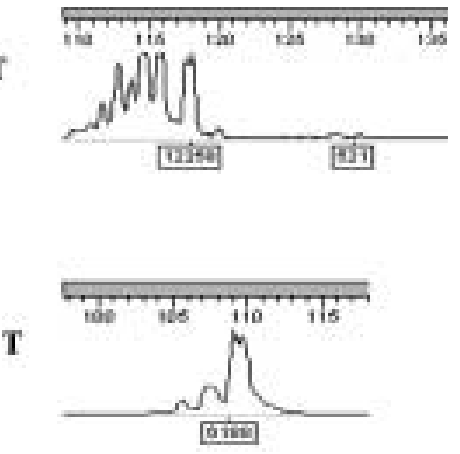

$\mathbf{T}$
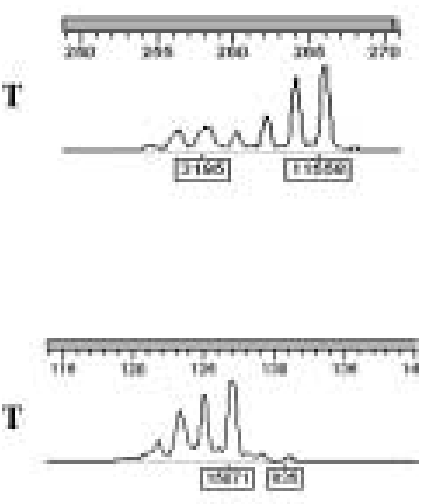

$\mathbf{T}$

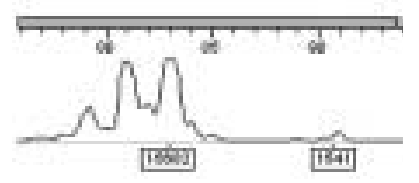

Figure 3 Electropherograms showing $\mathrm{LOH}$ in struma ovarii. LOH values were calculated from the height of the major peak of each allele (numbers in boxes). Microsatellite markers D7S640, D10S196, D10S1686, DXS990 and DXS1227 are located at 7q33, 10q11.23, 10q23.1, Xq21.32 and Xq27.2 respectively. $\mathrm{N}$ is the matched normal tissue and $\mathrm{T}$ is the tumor tissue. 
D18S61, D19S209, D19S884, D19S571, D20S889, D20S196, D21S914 and D22S283. For chromosomes 10 and X, we used D10S547, D10S1653, D1OS548, D10S197, D10S208, D10S196, D10S1652, D10S537, D10S1686, D10S185 and D10S192; and DXS1060, DXS8051, DXS987, DXS1226, DXS1214, DXS1068, DXS993, DXS991, DXS986, DXS990, DXS1106, DXS8055, DXS1001, DXS1047, DXS1227, DXS8043, DXS8091 and DXS1073, respectively. PCR was performed in a $7.5 \mu \mathrm{l}$ reaction volume containing $0.17 \mu \mathrm{M}$ each of HEX-labeled forward and unlabeled reverse primer (Invitrogen, Carlsbad, CA, USA), $4 \mathrm{mM}$ $\mathrm{MgCl}_{2}, 0.3$ units AmpliTaq Gold polymerase and $1 \times$ buffer II (Applied Biosystems), $250 \mu \mathrm{M}$ dNTPs (Invitrogen), and $15 \mathrm{ng}$ of genomic DNA. Amplification was performed in a DNA Engine Tetrad (MJ Research, Incline Village, NV, USA) with an initial denaturation of $95^{\circ} \mathrm{C}$ for $10 \mathrm{~min}$, followed by 10 cycles of $94^{\circ} \mathrm{C}$ for $15 \mathrm{~s}, 55^{\circ} \mathrm{C}$ for $15 \mathrm{~s}$ and $72^{\circ} \mathrm{C}$ for $30 \mathrm{~s} ; 20$ cycles of $89^{\circ} \mathrm{C}$ for $15 \mathrm{~s}, 55^{\circ} \mathrm{C}$ for $15 \mathrm{~s}$ and $72^{\circ} \mathrm{C}$ for $30 \mathrm{~s}$; and a final extension at $72{ }^{\circ} \mathrm{C}$ for $10 \mathrm{~min}$. A volume of $1 \mu \mathrm{l}$ of each amplicon was added to $10 \mu \mathrm{l}$ of Hi-Di formamide (Applied Biosystems) and $0.2 \mu \mathrm{l}$ of ROX 400HD size standard (Applied Biosystems), denatured at $95^{\circ} \mathrm{C}$ for $5 \mathrm{~min}$ and loaded into an ABI Prism 3700 Genetic Analyser (Applied Biosystems). LOH was assessed using Genescan v. 3.7 and Genotyper v. 3.7 software (Applied Biosystems). LOH was defined according to the following formula: $\mathrm{LOH}$ index $=(\mathrm{T} 2 / \mathrm{T} 1) /(\mathrm{N} 2 / \mathrm{N} 1)$, where $\mathrm{T}$ was the tumor sample, $\mathrm{N}$ was the matched normal sample, and 1 and 2 were the intensities of smaller and larger alleles respectively. If the ratio was under 0.67 or over 1.3 , the result was determined to be LOH. We found LOH at 4p15.2 (D4S391), 7p21.3-7q33 (D7S513, D7S640), 10q11.23 (D10S196), $\quad$ 10q23.1 (D10S1686), $\quad 13 \mathrm{q} 12.11$ $\begin{array}{lll}\text { (D13S175), } & 14 \mathrm{q} 11.2 \quad \text { (D14S283), } & 16 \mathrm{q} 23.1\end{array}$ (D16S515), Xp22.1-Xq21.32 (DXS1226, DXS991, DXS986, DXS990) and Xq27.2 (DXS1227) (Fig. 3).

\section{Discussion}

Struma ovarii is a rare ovarian teratoma that consists mainly of thyroid tissue, biologically and microscopically identical to normal thyroid (10).

Benign and malignant, struma ovarii represent $0.3-1 \%$ of all ovarian neoplasms and $2-4 \%$ of all ovarian teratomas $(1,2)$. Most patients are diagnosed because of an ascitic syndrome or a pelvic tumoral mass, whereas hyperthyroidism, with low radioiodine uptake in the thyroid bed, is present in only about $5-15 \%$ of cases $(2,11,12)$.

The case we report has the peculiarity of involving two different mechanisms of hyperthyroidism. The first mechanism is the occurrence of a toxic thyroid adenoma, according to ultrasonographic and scintigraphic evidence of a hot nodule, confirmed by transient hypothyroidism and a blunted cervical scintigraphy after radioiodine treatment. Second, unexpectedly, we found thyrotoxicosis of new onset due to atypical hyperthyroidism, as demonstrated by a whole-body scan with ${ }^{123} \mathrm{I}$, clearly depicting a pelvic uptake suggestive of an ectopic source of thyroid hormone production. Pelvic ultrasonography and MRI detected a cystic mass $12 \mathrm{~cm}$ in diameter, and specific pathologic examination identified a restraint mass, $3 \mathrm{~cm}$ in size, containing thyroid tissue.

The synchronous presentation of thyroid toxic adenoma and struma ovarii is an extremely rare condition. Two previous cases of struma ovarii described in a series of 25 patients were diagnosed after thyroidectomy for Plummer's disease (11). Nevertheless, these cases were diagnosed before 1970, and the contribution of teratomas to the thyrotoxic state seems difficult to assess retrospectively (13). The coexistence of struma ovarii and Graves' disease has rarely been described (14).

As previously stated, struma ovarii has been found to be biochemically and histologically identical to the thyroid tissue. This case also suggests that hyperfunctioning struma ovarii can have a clinical presentation similar to that of thyroid toxic adenoma. The underlying patho-physiological mechanisms of autonomous thyroid nodules have been described only recently. Thyroid toxic adenomas were found to be the consequence of monoclonal proliferation (15). As thyroid cell proliferation is mainly regulated by TSH and the way of cAMP, mutations of TSHR and Gs- $\alpha$ protein were investigated in toxic adenomas (16). In a Belgian series of 33 thyroid toxic adenomas, TSHR and Gs- $\alpha$ mutations were found in $82 \%$ and $6 \%$ of hyperfunctioning tumors respectively (6), as confirmed by other studies $(17,18)$. Therefore, we have initially tested these hypotheses in this struma ovarii, but we were unable to identify any mutation of TSHR or Gs- $\alpha$ coding genes. This evidence suggests that (an)other mutation(s) as yet unknown or (an)other pathophysiological mechanism(s) could be implicated in the development of the hyperthyroidism caused by struma ovarii.

The struma ovarii is biochemically and histologically identical to thyroid tissue. However, it is a benign neoplasia that develops during embryogenesis. Is it monoclonal in analogy with other teratomas?

Theories on the origin of ovarian teratomas are controversial. Earlier studies showed that teratoma cells are homozygous for enzyme markers that are heterozygous in host cells (19), suggesting that teratomas arise from a single germ cell during the meiotic process. Later studies showed that distal loci of chromosome arms from benign ovarian teratomas are heterozygous for genetic recombination during the long prophase of meiosis I, whereas centromeric markers are homozygous, suggesting that teratomas might originate from a germ cell that had completed the first meiotic division but failed the second $(20,21)$. However, other studies 
could not detect any homozygous genetic composition of teratomas while identifying heterozygous centromeric markers in a subset of the tumors, suggesting the possibility of either a postmeiotic or a premeiotic origin of these tumors $(4,22)$. Currently, the origin of teratomas remains debatable, but, generally, they appear to originate from a single germ cell after a defective meiosis, with a low incidence of numerical and/or structural chromosomal aberrations $(3,4)$.

As already mentioned, the struma ovarii is a rare ovarian teratoma; thus, genetic studies are very scant. In this case, we have had the opportunity to employ the most recent genetic techniques, probably for the first time.

We evaluated clonality using the AR. The struma ovarii cells displayed a LOH for the AR, as also confirmed by the LOH analysis of chromosome X (LOH at Xp22.1-Xq21.32), suggesting the monoclonality of this tumor and that it derives from a single germ cell.

Furthermore, we analyzed the cytogenetic features of the struma ovarii, using CGH and 'conventional' LOH analysis to detect possible chromosomal anomalies. CGH could not detect any chromosomal anomalies, but several chromosomal alterations were identified by using $\mathrm{LOH}$, confirming the sensitivity of the $\mathrm{LOH}$ approach. Our results showed multiple loss of regions in chromosomes $4,7,10,13,14,16$ and X. Other cytogenetic analysis of mature ovarian teratomas showed a very low incidence of numerical and/or structural aberrations $(5-7 \%)$ with no consistency or recurrency $(4,23,24)$. Furthermore, some reports described chromosomal anomalies in mature ovarian teratomas that undergo malignant transformation $(23,24)$.

Some of the chromosomal anomalies described here have been previously reported in other cases of mature teratomas. However, some of them were also described in immature teratomas and in benign mature teratomas that undergo malignant transformation. Noumoff et al. observed a $\operatorname{del}(\mathrm{X})(\mathrm{q} 11)$ in the malignant squamous component of an ovarian teratoma (24). Loss of heterozygosity on $\mathrm{Xq}$ is a common event in ovarian tumors and contributes to the progression of the tumor to an undifferentiated stage or aggressive behavior $(25,26)$. Chromosome 10 also seems to be involved in the malignant transformation of mature ovarian teratomas (23). We report, for the first time, consistent chromosomal changes on chromosome 7 . Therefore, our results reveal several structural chromosomal abnormalities in contrast to normal karyotypes in the majority of benign ovarian teratomas. Some of the anomalies are consistent with those described in immature teratomas as well as in some benign teratomas that undergo malignant transformation. To date, our patient has been followed up for 5 years with no evidence of malignancy. Further studies are required in order to verify whether specific chromosomal aberrations are correlated with the origin of teratomas and with the risk of malignant transformation.
In conclusion, to our knowledge, this is the first report of thyrotoxic struma ovarii revealed after treatment of a single thyroid toxic adenoma, illustrating to clinicians how a tree may hide a forest. This peculiar case allowed us to gain further insights into the pathophysiology of this teratoma and of struma ovarii-induced hyperthyroidism. We have shown in this case that 1) struma ovarii, part of a unique group of tumors, originate from a single germ cell; 2) albeit benign, they present several chromosomal abnormalities (mostly deletions); and 3) struma ovarii-induced hyperthyroidism is likely to be mediated by mechanisms different from those of the classical thyroid toxic adenoma.

\section{Acknowledgements}

The authors thank Prof. Gilbert Vassart (Institute of Interdisciplinary Research, Campus Erasme, Brussels University, Belgium) for his support to the TSH-receptor and Gs $\alpha$ subunit mutational studies; Dr Vinciane Dideberg (Wallonia Center for Human Genetics, Liège University, Liège, Belgium) for her support of the genetic studies; Dr Pascale Quatresooz (Department of Pathology, Liège University, Liège, Belgium) for the pathologic studies; Prof. Bin Tean Teh (Van Andel Research Institute, Grand Rapids, MI, USA) for his support of the CGH and LOH studies; and Prof. Alain Verloes (Department of Clinical Genetics, Robert Debrè Hospital, Paris, France) for stimulating discussion and helpful comments on the manuscript.

\section{References}

1 Ross DS. Syndromes of thyrotoxicosis with low radioactive iodine uptake. Endocrinology and Metabolism Clinics of North America 199827 169-185.

2 Ayhan A, Yanik F, Tuncer R, Tuncer ZS \& Ruacan S. Struma ovarii. International Journal of Gynaecology and Obstetrics 1993 $42143-146$.

3 Vortmeyer AO, Devouassoux-Shisheboran M, Li G, Mohr V, Tavassoli F \& Zhuang Z. Microdissection-based analysis of mature ovarian teratoma. American Journal of Pathology 1999 $154987-991$.

4 Surti U, Hoffner L, Chakravarti A \& Ferrell RE. Genetics and biology of human ovarian teratomas. I Cytogenetic analysis and mechanism of origin. American Journal of Human Genetics 1990 47 635-643.

5 de Roux N, Misrahi M, Chatelain N, Gross B \& Milgrom E. Microsatellites and PCR primers for genetic studies and genomic sequencing of the human TSH receptor gene. Molecular and Cellular Endocrinology $1996117253-256$.

6 Parma J, Duprez L, Van Sande J, Hermans J, Rocmans P, Van Vliet G et al. Diversity and prevalence of somatic mutations in the thyrotropin receptor and Gs alpha genes as a cause of toxic thyroid adenomas. Journal of Clinical Endocrinology and Metabolism 199782 2695-2701.

7 Lyons J, Landis CA, Harsh G, Vallar L, Grunewald K, Feichtinger H et al. Two $\mathrm{G}$ protein oncogenes in human endocrine tumors. Science $1990 \mathbf{2 4 9} 655-659$.

8 Allen RC, Zoghbi HY, Moseley AB, Roseblatt HM \& Belmont JW. Methylation of HapII and HhaI sites near the polymorphic CAG repeat in the human androgen receptor gene correlates with $\mathrm{X}$ 
chromosome inactivation. American Journal of Human Genetics 199251 1229-1239.

9 Kallioniemi A, Kallioniemi OP, Sudar D, Rutovitz D, Gray JW, Waldman F et al. Comparative genomic hybridization for molecular cytogenetic analysis of solid tumors. Science $1992 \mathbf{2 5 8}$ 818-821.

10 Dunzendorfer T, de Las Morenas A, Kalir T \& Levin RM. Struma ovarii and hyperthyroidism. Thyroid 19999 499-502.

11 Kempers R, Dockerty M, Hoffman D \& Bartholomew L. Struma ovarii - ascitic, hyperthyroid and asymptomatic syndromes. Annals of Internal Medicine 197072 883-889.

12 Devaney K, Snyder R, Norris HJ \& Tavassoli FA. Proliferative and histologically malignant struma ovarii: a clinicopathologic study of 54 cases. International Journal of Gynaecological Pathology $199312333-343$.

13 Hamburger JI. Pitfalls in the laboratory diagnosis of atypical hyperthyroidism. Archives of Internal Medicine 1979139 96-98.

14 Mimura Y, Kishida M, Masuyama H, Suwaki N, Kodama J, Otsuka F et al. Coexistence of Graves' disease and struma ovarii: case report and literature review. Endocrine Journal $2001 \mathbf{4 8}$ 255-260.

15 Dremier S, Coppee F, Delange F, Vassart G, Dumont JE \& Van Sande J. Thyroid autonomy: mechanism and clinical effects. Journal of Clinical Endocrinology and Metabolism $1996 \mathbf{8 1}$ 4187-4193.

16 Parma J, Duprez L, Van Sande J, Cochaux P, Gervy C, Mockel J et al. Somatic mutations in the thyrotropin receptor gene cause hyperfunctioning thyroid adenomas. Nature $1993 \mathbf{2 6 5} 649-651$.

17 Porcellini A, Ciullo I, Laviola L, Amabile G, Fenzi G \& Avvedimento VE. Novel mutations of thyrotropin receptor gene in thyroid hyperfunctioning adenomas. Rapid identification by fine needle aspiration biopsy. Journal of Clinical Endocrinology and Metabolism 1994 79 657-661.

18 Russo D, Arturi F, Wicker R, Chazenbalk GD, Schlumberger M, DuVillard JA et al. Genetic alterations in thyroid hyperfunctioning adenomas. Journal of Clinical Endocrinology and Metabolism 1995 80 1347-1351.

19 Linder D \& Power J. Further evidence for post-meiotic origin of teratomas in the human female. Annals of Human Genetics 197034 $21-30$.

20 Dahl N, Gustavson KH, Rune C, Gustavsson I \& Pettersson U. Benign ovarian teratomas. An analysis of their cellular origin. Cancer Genetics and Cytogenetics 199046 115-123.

21 Patil SR, Kaiser-McCaw B, Hecht F, Linder D \& Lovrien EW. Human benign ovarian teratomas: chromosomal and electrophoretic enzyme studies. Birth Defects 197814 297-301.

22 Carritt B, Parrington JM, Welch HM \& Povey S. Diverse origins of multiple ovarian teratomas in a single individual. PNAS 198279 7400-7404.

23 Riopel MA, Spellerberg A, Griffin CA \& Perlman EJ. Genetic analysis of ovarian germ cell tumors by comparative genomic hybridization. Cancer Research 199858 3105-3110.

24 Noumoff JS, LiVolsi VA, Deger RB, Montone KT \& Faruqi SA. Chromosome analysis and comparison of the benign cystic and malignant squamous component of an ovarian teratoma. Cancer Genetics and Cytogenetics 2001125 59-62.

25 Choi C, Cho S, Horikawa I, Berchuck A, Wang N, Cedrone E et al. Loss of heterozygosity at chromosome segment Xq25-26.1 in advanced human ovarian carcinomas. Genes Chromosomes Cancer 199720 234-242.

26 van den Berg-Bakker CA, Hagemeijer A, Franken-Postma EM, Smit VT, Kuppen PJ, van Ravenswaay Claasen HH et al. Establishment and characterization of 7 ovarian carcinoma cell lines and one granulosa tumor cell line: growth features and cytogenetics. International Journal of Cancer 199353 613-620.

Received 31 October 2003

Accepted 31 December 2003 